\section{Marginal zone lymphoma: present status and future perspectives}

\author{
Chan Y. Cheah,,$^{1,2}$ Emanuele Zucca, ${ }^{3}$ Davide Rossi ${ }^{4}$ and Thomas M. \\ Habermann ${ }^{5}$ \\ ${ }^{1}$ Department of Haematology, Sir Charles Gairdner Hospital, Nedlands, Western Australia, \\ Australia; ${ }^{2}$ Medical School, University of Western Australia, Crawley, Western Australia, \\ Australia; ${ }^{3}$ Oncology Institute of Southern Switzerland, University of Bern and International \\ Extranodal Lymphoma Study Group, Director of Operation Office, Bern, Switzerland; \\ ${ }^{4}$ Laboratory of Experimental Hematology, Institute of Oncology Research, Bellinzona, \\ Switzerland and ${ }^{5}$ Department of Internal Medicine, Division of Hematology, Mayo Clinic, \\ Rochester, MN, USA
}

\section{Introduction}

Marginal zone lymphomas (MZL) are collectively the second most common indolent lymphoma comprising $7 \%$ of all non-Hodgkin lymphomas with 7,460 patients diagnosed in the USA in 2016 ${ }^{1-3}$ There are three distinct subtypes: extranodal MZL of mucosa-associated lymphoid tissue (MALT lymphoma), which accounts for $50-70 \%$ of cases, splenic MZL (20\%) and nodal MZL (10\%).,5 The optimal treatment in many cases is not well defined because of the diversity of clinical presentation, incomplete understanding of the underlying disease biology and tendency to group MZL with follicular lymphoma in clinical trials. In this review, we provide an overview of the biology, epidemiology, clinical presentation, current management strategies and emerging data for novel agents in the management of relapsed/refractory disease.

The epidemiology and natural history of MZL remain poorly understood. ${ }^{6} \mathrm{~A}$ family history of lymphoma is a salient risk factor for MZL. Genetic and environmental risk factors for extranodal MZL include infectious agents and autoimmune disorders such as Sjögren syndrome, systemic lupus erythematosus and Hashimoto thyroiditis. ${ }^{3}$ Preliminary data suggest a significant risk factor for nodal MZL is being a metal worker (odds ratio 3.6), whereas significant risk factors for splenic MZL include asthma (odds ratio 2.3) and use of hair dye (odds ratio 6.5).

\section{Extranodal marginal zone lymphoma of mucosa-associated lymphoid tissue (MALT lymphoma)}

MALT lymphoma is often caused by chronic antigenic stimulation by infectious pathogens or autoimmunity leading to inflammatory lymphoid populations and can arise in widely varied sites. ${ }^{5}$ Gastric MALT accounts for more than $30 \%$ of cases. ${ }^{8}$ Other common sites include the ocular adnexa, salivary glands, skin, conjunctiva, lungs, thyroid and breasts, with diverse site-specific etiologies. ${ }^{2}$ The strongest evidence for a specific etiological pathogen relates to Helicobacter pyloriinduced chronic gastritis implicated in around two-thirds of cases of gastric MALT lymphoma. Autoimmune diseases such as Sjögren syndrome and Hashimoto thyroiditis are associated with increased risk of MALT lymphoma of the salivary gland and thyroid, respectively. The clinical presentation of MALT lymphoma varies widely according to the site(s) of involvement. Typically, MALT lymphoma has an indolent behavior and favorable outcomes. ${ }^{1}$ In MALT lymphoma, particularly gastric, contact with foreign antigens and mucosal permeability are likely important. ${ }^{9}$ Although most MALT lymphomas are localized, around $20 \%$ are stage IV and extranodal dissemination is typical in this case. Other infections associated with MALT lymphoma include hepatitis $C$ virus, Chlamydophila psittaci (previously Chlamydia) in the conjunctiva and ocular adnexa, Borrelia burgdorferi in the skin, and Achromobacter xylosoxidans in the lungs. Histological transformation of extranodal MZL is associated with an inferior prognosis and may be driven by TP53 mutations, loss of p16 protein, or rearrangements in $M Y C^{10,11}$ Critical signals required to support growth of marginal zone B cells include BAFF, CD40, TLR, BCR, and NOTCH receptor signaling. Chronic antigenic stimulation through infection or autoimmunity can drive B-cell receptor stimulation, biased immunoglobulin heavy chain gene usage, as well as genetic abnormalities in signaling pathways
Ferrata Storti Foundation

Haematologica 2022

Volume 107(1):35-43

\section{Correspondence:}

CHAN CHEAH

chan.cheah@health.wa.gov.au

Received: September 10, 2021.

Accepted: November 3, 2021.

https://doi.org/10.3324/haematol.2021.278755

(C)2022 Ferrata Storti Foundation

Material published in Haematologica is covered by copyright. All rights are reserved to the Ferrata Storti Foundation. Use of published material is allowed under the following terms and conditions:

https://creativecommons.org/licenses/by-nc/4.0/legalcode. Copies of published material are allowed for personal or internal use. Sharing published material for non-commercial purposes is subject to the following conditions:

https://creativecommons.org/licenses/by-nc/4.0/legalcode, sect. 3. Reproducing and sharing published material for commercial purposes is not allowed without permission in writing from the publisher. 
that regulate the NFKB pathway including $t(1 ; 14)$, $\mathrm{t}(11 ; 18), A 20$ inactivation and MYD 88 mutations. ${ }^{12}$

\section{Diagnosis and staging}

MALT lymphomas characteristically remain localized for prolonged periods although multi-focal single organ involvement and systemic dissemination can occur in up to $25 \%$ of cases (more likely with non-gastric sites). ${ }^{5,13}$ Patients with advanced stage disease have an inferior prognosis and require different therapeutic strategies from patients with localized disease. ${ }^{8}$ Thus, careful staging is required and the diagnostic work-up should be tailored according to the site involved and any possible underlying infectious or autoimmune causes. ${ }^{5}$ Bone marrow involvement is present in fewer than $10 \%$ of patients with initially localized MALT lymphoma and patients without cytopenias can possibly be spared this procedure as those with radiologically defined stage IE disease have excellent lymphoma-specific outcomes irrespective of whether bone marrow biopsy is performed or not..$^{14.15}$ The MALT International Prognostic Index (MALT-IPI) identified three factors (advanced stage disease, age $\geq 70$ years, and elevated lactate dehydrogenase) that may be useful for prognostication. ${ }^{16}$

\section{Current treatment approaches \\ Localized disease}

Gastric MALT lymphoma

In patients positive for $H$. pylori infection, standard eradication therapy with a proton pump inhibitor plus dual or triple antibiotics should be instituted. H. pylori eradication alone causes regression of gastric MALT lymphoma in $75 \%$ of cases. ${ }^{5}$ Re-testing at 2 months with a breath test can be considered - following cessation of proton pump inhibitors for at least 1 month - to ensure eradication before re-assessing the lymphoma status endoscopically 3 months after eradication. ${ }^{17,18}$ Waiting for 3 months for repeat endoscopy is important, as earlier evaluation may not reflect the eventual disease response. Patients with tumors carrying the $\mathrm{t}(11 ; 18)$ translocation have a lower response rate to $H$. pylori eradication and alternative approaches (see below) should be considered for these patients. ${ }^{19}$

For patients with localized disease who are H. pylorinegative, empiric eradication therapy may still be beneficial in a significant proportion of patients. ${ }^{20}$ Similarly, clarithromycin therapy has resulted in meaningful response rates in some patients with gastric MALT lymphoma. ${ }^{21}$

In cases in which eradication therapy has failed, involved site radiotherapy is a reasonable approach with favorable outcomes using moderate doses (24-30 Gy over 3-4 weeks). ${ }^{17,22}$ One study which included patients with localized gastric or non-gastric MALT lymphoma reported 10-year overall and recurrence-free survival rates of $87 \%$ and $76 \%$, respectively, with cause-specific survival of $98 \% .^{23}$ Other treatment options include rituximab monotherapy, ${ }^{24}$ and chemo-immunotherapy such as rituximab plus chlorambucil ${ }^{25}$ or rituximab plus cyclophosphamide, vincristine and prednisolone (R-CVP). ${ }^{18}$ Gastrectomy results in significant morbidity and is no longer recommended.

\section{Non-gastric MALT lymphoma}

Patients with localized disease in other sites associated with a postulated causative pathogen should be consid- ered for eradication therapy, although the etiological relationship and outcomes following eradication are less well established. Some investigators have found ocular adnexal MALT to be associated with C. psittaci with considerable geographic variability. ${ }^{26}$ Doxycycline or clarithromycin has resulted in response rates of $45-65 \%{ }^{27}$ Furthermore, disease regression using antibiotics has been reported in C. psittaci-negative cases. ${ }^{28}$ Thus testing and an empiric trial of eradication can be considered. Data regarding response rates to antibiotics in the other subtypes are scant, and no firm conclusions can be drawn. In contrast to other lymphomas, radiation therapy has a significant role in extranodal MZL. ${ }^{29}$ The phase II Trans-Tasman Radiation Oncology Group/Australasian Leukemia and Lymphoma Group 05.02 trial established that involved field radiotherapy is a reasonable treatment for localized non-gastric MALT lymphoma, resulting in 5year progression free survival (PFS) and overall survival (OS) of $79 \%$ and $95 \%$ respectively. ${ }^{30}$ Outcomes of dural MZL have been reported to be favorable following radiation therapy. ${ }^{31,32}$ Extranodal MALT of the thyroid, small bowel, colon, and rectum have been managed with observation, surgical resection, radiation therapy, and rituximab. MALT lymphoma of the salivary glands has an excellent prognosis irrespective of the primary therapy. ${ }^{33}$ According to National Comprehensive Cancer Network guidelines, surgery may be considered for lymphomas in certain sites and some selected asymptomatic patients can also be observed. ${ }^{34}$

\section{Advanced stage disease}

Advanced stage MZL of MALT type is incurable and the usually indolent biology allows for a 'watch and wait' approach in many patients. When treatment is required, systemic chemo-immunotherapy has been used successfully. The addition of rituximab to chlorambucil improved outcomes compared to either agent alone ${ }^{25} \mathrm{R}$ CVP followed by rituximab maintenance has been shown to be well tolerated and effective. ${ }^{35}$ Bendamustine and rituximab was safe and effective in a phase II trial of 60 patients with a median follow-up of 43 months. ${ }^{36}$ Eventfree survival was $88 \%$ at 4 years. A USA-Italian observational series $(n=136)$ confirmed these observations, with estimated 5-year PFS and OS of $72.3 \%$ and $85.6 \%$, respectively. ${ }^{37}$ Similar results were evident from German prospective registry data. ${ }^{38}$

\section{Nodal marginal zone lymphoma}

Nodal MZL is the least common of all the subtypes of MZL, accounting for approximately $10 \%$ of MZL and $<2 \%$ of all non-Hodgkin lymphomas. ${ }^{2,39}$ The median age at presentation is 60 years and both genders are equally affected..$^{40}$ The understanding of nodal MZL has been hampered by its rarity, with therapeutic strategies largely based on data from follicular or small lymphocytic lymphoma. In common with these disorders, the disease generally behaves in an indolent fashion and is often disseminated at presentation. Histological transformation is reported in $3-15 \%$ of patients with nodal MZL and is often associated with a poor outcome. ${ }^{41}$ While there is an association with hepatitis $\mathrm{C}$ infection, ${ }^{42}$ a history of autoimmunity is less common than with other forms of MZL. ${ }^{43}$ 


\section{Diagnosis and staging}

Peripheral lymphadenopathy involving the head and neck is common at presentation, with up to one third of patients having bulky tumors $(>5 \mathrm{~cm})$ and about half having stage III/IV disease.$^{43}$ Approximately $10 \%$ of patients will present with an IgM paraprotein ${ }^{39}$ which can result in the diagnosis being confused with Waldenström macroglobulinemia. The absence of an MYD88 L265P mutation (a feature of Waldenström macroglobulinemia) supports the diagnosis of nodal MZL although this mutation may also be observed in less than $10 \%$ of cases of nodal MZL. ${ }^{38}$ PTPRD mutations are observed in $20 \%$ of patients with nodal MZL and the finding appears specific to this entity. ${ }^{44}$

Nodal MZL demonstrates similar cytological, immunophenotypic and genetic features to those of both splenic and extranodal MZL which may result in diagnostic difficulty, particularly in cases with involvement of the spleen or extranodal sites. ${ }^{39}$ Validated prognostic scoring systems are lacking in nodal MZL, with conflicting data regarding the applicability of the Follicular Lymphoma International Prognostic Index (FLIPI) ${ }^{45,46}$ Increased age and advanced stage have been associated with an adverse prognosis. ${ }^{47}$

\section{Current treatment approaches}

The standard therapy for nodal MZL is yet to be defined with many centers employing strategies used in follicular lymphoma. Patients with localized disease respond well to radiotherapy, and those with minimally symptomatic, low tumor burden, advanced stage disease are suitable for a strategy of watchful waiting. ${ }^{39}$ Reports of regression of MZL with eradication of hepatitis C infection support this strategy as an initial approach in hepatitis $C$ virus-infected patients. ${ }^{48,49}$ Patients with disseminated disease and high tumor burden can be treated with chemo-immunotherapy. ${ }^{40}$

\section{Chemo-immunotherapy}

Despite the lack of prospective studies, chemoimmunotherapy with rituximab is generally considered standard treatment for patients with symptomatic advanced stage disease. Numerous regimens have been explored including R-CVP, ${ }^{50}$ rituximab, cyclophosphamide, doxorubicin, vincristine and prednisone ( $R$ CHOP), ${ }^{51}$ fludarabine and rituximab, ${ }^{52}$ fludarabine, cyclophosphamide and rituximab $b^{53}$ and bendamustine and rituximab. ${ }^{51,54}$ Fludarabine regimens are not routinely utilized because of toxicities.

\section{Splenic marginal zone lymphoma}

Splenic MZL makes up less than $2 \%$ of all lymphoid malignancies, and $20 \%$ of all MZL. It is usually indolent, with a median survival of 8-10 years, but can transform to diffuse large B-cell lymphoma in approximately $5-10 \%$ of cases. ${ }^{2,55}$ Approximately one third of patients have no symptoms, and a watch and wait approach has no adverse impact on overall survival..$^{56}$ The subtypes and the biology and function of the splenic marginal zone B cell remain poorly understood. Splenic marginal zone B cells bridge the gap between early innate immune responses and late adaptive immune responses. Marginal zone B cells are sustained in their local microenvironment by cytokine-secreting cells such as group 3 innate lymphoid cells, which produce copious amounts of the cytokine $\mathrm{BAFF}$ and induce $\operatorname{IgM}, \operatorname{Ig} \mathrm{G}$, and $\operatorname{Ig} \mathrm{A}$ production in marginal zone B cells.

NOTCH pathway genes are mutated in splenic MZL and nodal MZL, in addition to other marginal zone differentiation-associated genes, in as many as $60 \%$ of patients. ${ }^{57} \mathrm{~A}$ common mutation in splenic MZL occurs in the KLF2 transcription factor, leading to activation of NF$\kappa B$ signaling with further hits to TRAF3, MAP3K14, and BIRC 3. ${ }^{11}$ Distinguishing splenic MZL from other CD5and CD10-negative indolent B-cell lymphoproliferative disorders can be challenging, with a definitive diagnosis best achieved with spleen histology. ${ }^{55}$ However, in most patients, the diagnosis can be suggested by the characteristic morphology of peripheral blood lymphocytes with bipolar cytoplasmic villous projections and a round nucleus (in contrast to hairy cell leukemia in which cells have circumferential projections and an ovoid nucleus).

\section{Diagnosis and staging}

Immunophenotyping of circulating or bone marrow lymphocytes demonstrates IgM +/- IgD, CD19, CD20, CD22 and BCL-2 expression. CD23, CD25, and CD103 and cyclin D1 negativity assist in excluding chronic lymphocytic leukemia, mantle cell and hairy cell leukemia (which also causes prominent splenomegaly). In common

Table 1. Selected phase II studies evaluating novel agents in patients with relapsed/refractory marginal zone lymphoma. Efficacy data from the publication with longest follow-up reported where available.

\begin{tabular}{|c|c|c|c|c|c|c|c|c|c|c|c|}
\hline Class & Agent & First author & $\begin{array}{l}\text { N. of MZL } \\
\text { cases }\end{array}$ & $\begin{array}{c}\text { Median } \\
\text { age } \\
\text { (years) }\end{array}$ & $\begin{array}{l}\text { Median } \\
\text { prior } \\
\text { lines }\end{array}$ & $\begin{array}{c}\text { Extranodal / } \\
\text { nodal / } \\
\text { splenic (\%) }\end{array}$ & $\begin{array}{l}\text { ORR } \\
(\%)\end{array}$ & $\begin{array}{l}\text { CR } \\
(\%)\end{array}$ & $\begin{array}{l}\text { Median } \\
\text { DOR } \\
\text { (months) }\end{array}$ & $\begin{array}{c}\text { Medlan } \\
\text { PFS } \\
\text { (months) }\end{array}$ & $\begin{array}{c}\text { OS } \\
\text { (months) }\end{array}$ \\
\hline BTK inhibitor & $\begin{array}{c}\text { ibrutinib } \\
\text { zanubrutinib }\end{array}$ & $\begin{array}{l}\text { Noy }^{79,80} \\
\text { Opat }^{83}\end{array}$ & $\begin{array}{l}63 \\
68\end{array}$ & $\begin{array}{l}66 \\
70\end{array}$ & $\begin{array}{l}2 \\
2\end{array}$ & $\begin{array}{l}51 / 27 / 22 \\
38 / 38 / 18\end{array}$ & $\begin{array}{l}58 \\
74\end{array}$ & $\begin{array}{c}3 \\
24\end{array}$ & $\begin{array}{c}27.6 \\
12 \mathrm{~m} \text { DOR } \\
81 \%\end{array}$ & $\begin{array}{c}15.7 \\
15 \mathrm{~m} \text { PFS } \\
68 \%\end{array}$ & $\begin{array}{l}\mathrm{NE} \\
\mathrm{NA}\end{array}$ \\
\hline PI3K inhibitor & $\begin{array}{l}\text { idelalisib } \\
\text { copanlisib } \\
\text { umbralisib } \\
\text { parsaclisib }\end{array}$ & $\begin{array}{c}\text { Gopal }^{84} \text { Martin }^{85} \\
\text { Dreyling }^{89} \\
\text { Panayiotidis }^{90} \\
\text { Fowler }^{91} \\
\text { Phillips }^{92}\end{array}$ & $\begin{array}{l}15 \\
23 \\
69 \\
69 \\
99\end{array}$ & $\begin{array}{l}\text { NA } \\
69 \\
\\
67 \\
71\end{array}$ & $\begin{array}{c}\mathrm{NA} \\
3\end{array}$ & $\begin{array}{c}\mathrm{NA} \\
17 / 65 / 17\end{array}$ & $\begin{array}{l}43 \\
70 \\
\\
49 \\
54\end{array}$ & $\begin{array}{c}5 \\
13\end{array}$ & $\begin{array}{c}\text { NA } \\
17.4\end{array}$ & $\begin{array}{c}6.6 \\
24.1 \\
\\
\text { 2y PFS } 50.5 \% \\
13.8\end{array}$ & $\begin{array}{c}\text { NA } \\
2 y \text { OS } 83 \% \\
\text { NE } \\
\text { NA }\end{array}$ \\
\hline $\begin{array}{l}\text { Anti-CD19 } \\
\text { CAR T-cell }\end{array}$ & axi-cel & Jacobson $^{93}$ & 22 & 66 & 3 & NA & 85 & 60 & 10.6 & 11.8 & $\mathrm{NE}$ \\
\hline
\end{tabular}

MZL: marginal zone lymphoma; ORR, objective response rate; CR, complete response; DOR, duration of response; PFS, progression free survival; OS, overall survival; m: months; y: years: NA: not available; NE: not evaluable; BTK, Bruton tyrosine kinase; PI3K, phosphatidylinositol-3-kinase; axi-cel: . axicabtagene ciloleucel; CAR: T-cell: chimeric antigen receptor T-cell therapy. 
with nodal MZL, an IgM paraprotein may occur and MYD88 mutation testing can help distinguish splenic MZL from Waldenström macroglobulinemia. ${ }^{58}$ Hepatitis $\mathrm{C}$ infection should be treated if present as treatment can result in lymphoma regression. ${ }^{48}$ Splenic hilar lymphadenopathy occurs in $25 \%$ of cases of splenic MZL but peripheral lymphadenopathy is rare. ${ }^{59,60}$ Most patients present with splenomegaly, lymphocytosis and cytopenias. ${ }^{59}$ Autoimmune hemolytic anemia and other autoimmune phenomena can occur. Computed tomography (CT) scan is adequate for staging; positron emission tomography (PET) with CT can be reserved for patients in whom histological transformation is suspected. ${ }^{55}$

\section{Current treatment approaches}

Asymptomatic patients can be managed with observation. Symptomatic splenomegaly, cytopenia, systemic symptoms or progressive nodal disease are indications for treatment. ${ }^{55,56}$ Frontline treatment options include splenectomy, rituximab monotherapy, and chemo-immunotherapy. ${ }^{55}$ While these three approaches have not been directly compared, rituximab monotherapy or chemoimmunotherapy are typically preferred.

\section{Splenectomy}

Splenectomy was the mainstay of therapy before rituximab monotherapy was adopted, and its role in modern management is now often in the second-line setting or beyond. Nonetheless, splenectomy removes disease bulk, abdominal discomfort and improves cytopenias due to splenic sequestration which is more common than heavy marrow involvement. ${ }^{55}$ Splenectomy typically results in durable disease control and facilitates a definitive diagnosis of splenic MZL. ${ }^{55}$ Short-term perioperative complications may be reduced with a laparoscopic approach and prophylaxis against venous thromboembolism. The late risk of infections with encapsulated bacteria can be minimized with vaccinations at least 2 weeks before elective splenectomy and, potentially, prophylactic antibiotics. ${ }^{55}$

\section{Chemo-immunotherapy}

Chemo-immunotherapy is appropriate for fit patients with disseminated disease, constitutional symptoms, and/or high-grade transformation..$^{55}$ R-CVP and R-CHOP, both commonly used in follicular lymphoma, can be delivered to patients with splenic MZL; however, in a prospective phase II trial R-COMP (rituximab with cyclophosphamide, vincristine, non-pegylated liposomal doxorubicin and prednisone) resulted in an objective response rate (ORR) of $84 \%$ and a 6 -year PFS of $54 \% .^{55}$ Bendamustine and rituximab resulted in durable responses in the BRIGHT ${ }^{61}$ and STiL ${ }^{51}$ studies, and the use of rituximab maintenance for 2 years following initial treatment with bendamustine and rituximab in both nodal and splenic MZL prolonged PFS (but not OS) relative to no maintenance (hazard ratio $=0.35,95 \%$ confidence interval: $0.17-0.76, P=0.008)$ in the STiL NHL7-2008 MAINTAIN trial. ${ }^{62}$

\section{Single-agent rituximab}

Rituximab monotherapy resulted in an ORR of $92 \%$ and 10 -year freedom from progression of $64 \%$ in a large retrospective series. ${ }^{63}$ The RESORT trial treated patients with $375 \mathrm{mg} / \mathrm{m}^{2}$ weekly for 4 weeks and then randomized patients to observation versus maintenance ritux- imab. ${ }^{64}$ There was a significant improvement in time to treatment failure and PFS in the maintenance therapy arm. Single-agent rituximab (with short or protracted administration) has become the preferred approach in most patients, so that splenectomy or chemoimmunotherapy is reserved for patients not responding to single-agent treatment. ${ }^{65}$ Recent single institution data showed that CD5 expression, although rare in MZL, was associated with a lower ORR following rituximab monotherapy but not bendamustine and rituximab, suggesting the latter combination might be preferred if systemic therapy is required. ${ }^{66}$

\section{Histological transformation}

Histological transformation to diffuse large B-cell lymphoma is associated with a poor outcome and inferior overall survival. Histological transformation occurs with an annual incidence of approximately $1 \%$ per year. ${ }^{11}$ Failure to achieve complete remission, elevated lactate dehydrogenase concentration, more than four nodal sites involved at diagnosis, ${ }^{11}$ involvement of multiple mucosal sites, ${ }^{66}$ CD5 expression ${ }^{65}$ and in splenic MZL, complex karyotype, are associated with greater risk of histological transformation. ${ }^{67}$

\section{Mantle zone lymphoma assessment criteria and response evaluation}

Several classifications are used for treatment response assessment in MZL. CT-scan response assessment is not well defined in MZL, which is primarily an extranodal disease. Splenic MZL and gastric MZL, or MZL from other extranodal sites prove difficult to assess based on CT-scan criteria. Various response assessment criteria for these diseases, such as the Lugano, ${ }^{68}$ Matutes $^{69}$ and $\mathrm{GELA}^{70}$ classifications need to be homogenized, to facilitate better comparison of the results between different clinical trials. In localized gastric MZL, serial endoscopy and gastric biopsy are recommended, and responses can take up to 12 months. The presence of residual microscopic lymphoma prior to that time should not prompt initiation of another treatment if the patient has improved clinically and macroscopically. ${ }^{8}$

There is a wide range of endpoints that are currently used in clinical trials and in routine practice. ${ }^{71-73}$ However, the endpoints currently validated by the Food and Drug Administration (FDA) for use in phase II clinical trials are the ORR and complete response rate, which may not fully capture patients' outcomes in MZL. Surrogate endpoints in MZL may include PET-CT, minimal residual disease, and progression of disease within 2 years. ${ }^{74}$ The value of PET-CT and minimal residual disease criteria in assessing response to treatment in MZL requires further characterization.

The value of PET-CT in routine evaluation of MALT lymphoma remains unestablished. ${ }^{75}$ The sensitivity of PET-CT is highly variable in the disease, ranging from 50 $80 \%$ in various studies. ${ }^{76}$ Furthermore, fluorodeoxyglucose avidity in MZL is strongly dependent on the histopathological subtype. ${ }^{77}$ Nevertheless, PET-CT is useful because CT-based staging is of limited utility in the evaluation of extranodal disease. ${ }^{75}$ PET-CT is useful in 
staging MZL to confirm localized disease and ensure effective radiotherapy. However, gastric and ocular MALT possess low fluorodeoxyglucose avidity. In histologically transformed MZL, PET-CT is necessary to confirm transformation and PET-CT-based response criteria are also used in the Lugano classification to identify transformed MZL. ${ }^{78}$ Site-specific imaging is required to monitor response in MZL (for example, magnetic resonance imaging in ocular adnexal MALT).

\section{Novel agents in mantle zone lymphoma}

\section{Bruton tyrosine kinase inhibitors}

The covalent Bruton tyrosine kinase (BTK) inhibitor ibrutinib was approved for patients with relapsed/refractory MZL on the basis of the results of a phase II trial. ${ }^{79}$ Noy et al. treated 63 patients with a median age of 66 years and median of two prior lines of therapy. MALT lymphoma $(51 \%)$ was the most common subtype of MZL, followed by nodal MZL (27\%) and splenic MZL $(22 \%)$. Among the 60 patients in whom efficacy could be evaluated, the ORR was $48 \%$ (complete responses, 3\%) and consistent across disease subtypes. The median duration of response was not reached, while the median PFS was 14.2 months. The safety profile of ibrutinib was consistent with that following its use in other settings, with anemia (14\%), pneumonia (8\%) and fatigue $(6 \%)$ being the most common grade $\geq 3$ treatment-emergent adverse events (TEAE). Bleeding events occurred in 59\% of patients and were all grade 1-2 apart form one grade 5 cerebral hemorrhage that occurred in a patient therapeutically anticoagulated with dalteparin. Atrial fibrillation occurred in four patients $(6 \%)$. The long-term follow-up of this study was recently published, and after a median follow-up of 33.1 months the ORR was $58 \%$, the median duration of response was 27.6 months, the median PFS 15.7 months and the median OS had not been reached. ${ }^{80}$ The ORR for extranodal, nodal and splenic MZL was $63 \%, 47 \%$ and $62 \%$, respectively. Mutations in KMT2D and CARD11 were associated with shorter duration of response.

The B-cell lymphoma-2 (BCL2) inhibitor venetoclax showed activity in a phase I study of patients with relapsed/refractory lymphoma, including MZL. ${ }^{81}$ Although this agent has not been further explored as monotherapy in MZL, the combination of ibrutinib and venetoclax was investigated in a small phase II study. ${ }^{82}$ An interim analysis demonstrated an ORR of $84 \%$ (complete responses, 42\%) at week 16.

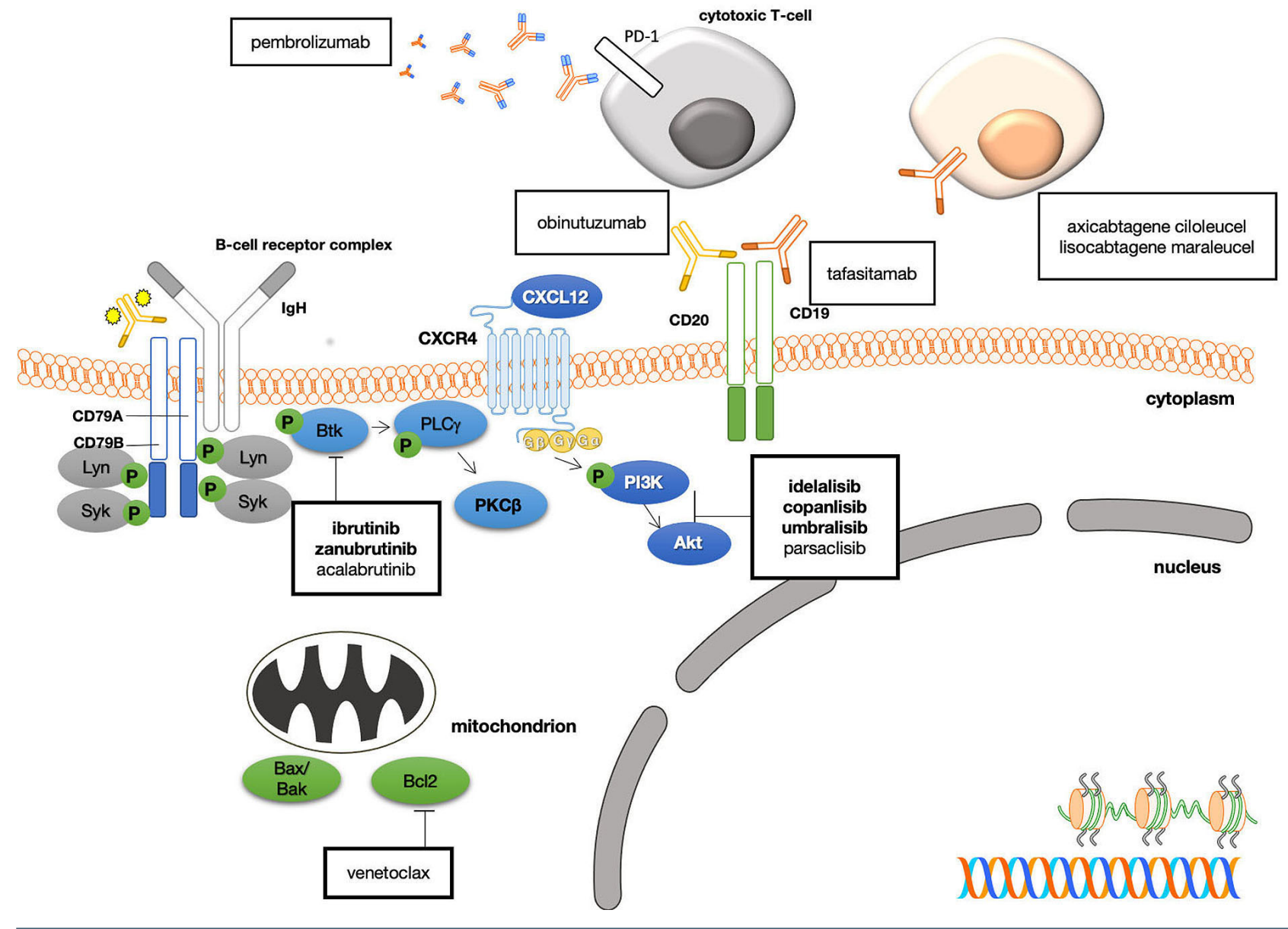

Figure 1. Mechanism of action of selected novel agents for the treatment of marginal zone lymphoma. Bold type indicates approved agents, normal type indicates agents under investigation. IgH: immunoglobulin heavy chain; CD: cluster of differentiation; Syk: spleen tyrosine kinase; Btk: Bruton tyrosine kinase; PLCү2: phospholipase Cy2; PKCB: protein kinase C $\beta$; PI3K: phosphatidylinositol-3-kinase; Akt: protein kinase B; bax: B-cell lymphoma-2 associated X protein; Bcl2: B-cell lymphoma protein-2; CAR: chimeric antigen receptor; PD-1, programmed cell death-1. Adapted from Cheah et al. J Clin Oncol 2016. 
The selective BTK inhibitor zanubrutinib was examined in a single-arm phase II study by Opat et al ${ }^{.3}$ Eligible patients with MZL who had had one or more prior line of therapy were treated with $160 \mathrm{mg}$ of zanubrutinib twice daily. Among the 68 patients, $38 \%$ had MALT lymphoma, 38\% had nodal MZL, 18\% had splenic MZL and $6 \%$ had an indeterminate subtype. Patients had received a median of two prior lines of therapy and the ORR was $68 \%$ (complete responses, 26\%) with similar rates between MZL subtypes. The estimated 15 month PFS rate was $82.5 \%$. The most common TEAE were diarrhea $(22 \%)$, bruising $(21 \%)$, and constipation $(15 \%)$ with neutropenia $(10 \%)$ being the most common grade $\geq 3 \mathrm{TEAE}$. Atrial fibrillation and hypertension each occurred in 3\% of patients. On the basis of these data zanubrutinib was recently approved for patients with relapsed MZL.

\section{Phosphatidylinositol-3-kinase inhibitors}

Three phosphatidylinositol-3-kinase (PI3K) inhibitors have been approved by the FDA for the treatment of relapsed/refractory MZL. The PI3Kס inhibitor idelalisib was the first-in-class agent, with significant activity in a range of indolent B-cell malignancies. In the phase II registration trial, Gopal et al. treated 125 patients with indolent lymphoma including 15 with MZL with $150 \mathrm{mg}$ of idelalisib orally twice daily. ${ }^{84}$ Efficacy was encouraging, but the infectious and immune toxicities were noteworthy. Although results for the subset of MZL patients were not reported separately in that study; Martin et al. reported pooled data from 21 patients treated in the phase I and phase II trials: two of six patients (both with partial responses) in phase I and seven of 15 (one with a complete response) in phase II achieved a response for a cumulative ORR of $43 \% .{ }^{85}$ The median PFS in phase II was 6.6 months and the toxicity profile was consistent with that observed in other histological subtypes. Although phase III trials in indolent lymphoma were commenced, the toxicity observed when combining idelalisib with chemo-immunotherapy and other novel agents was considerable and further clinical development was halted. ${ }^{86-88}$

Other PI3K inhibitors have been developed, including the intravenous pan-class I PI3K inhibitor copanlisib. In the phase II CHRONOS-1 study Dreyling et al. enrolled 142 patients with relapsed/refractory indolent B-cell lymphoma, of whom 23 had MZL. ${ }^{89}$ Patients received $60 \mathrm{mg}$ of copanlisib intravenously on days 1, 8 and 15 of 28-day cycles until disease progression or unacceptable toxicity. At the primary analysis after four cycles of therapy, the ORR was $70 \%$, resulting in breakthrough therapy designation for adults with MZL who had received two or more prior systemic therapies. Long-term follow-up of the 23 patients in this study with relapsed/refractory MZL was recently reported. ${ }^{90}$ These patients had a median age of 69 years and had received a median of three prior lines of therapy. The most common MZL subtype was nodal MZL ( $n=15)$ with four patients each having splenic and MALT lymphoma. The eventual ORR was $78 \%$, with the rates for nodal, splenic and MALT lymphoma being $87 \%, 75 \%$ and $50 \%$, respectively. Complete responses were observed in three $(13 \%)$ patients, all with splenic MZL. The median duration of response was 17.4 months; the median PFS was 24.1 months and the median OS was not reached. The estimated 2-year OS rate was $83 \%$. The most frequent TEAE of any grade were fatigue (52\%), diarrhea and hyperglycemia (each $48 \%$ ), while the most common grade $\geq 3$ TEAE were hyperglycemia, hypertension (each 39\%), fatigue, diarrhea, neutropenia and pneumonia (each $26 \%)$. The increase in infectious and immune toxicity observed with idelalisib was not apparent.

Umbralisib is a novel, oral, dual inhibitor of PI3Kס and casein kinase-1- $\varepsilon$, with minimal PI3K $\gamma$ inhibition, which is taken once daily. Fowler et al. performed a phase IIb registration trial of umbralisib $800 \mathrm{mg}$ daily in 208 patients with relapsed/refractory indolent B-cell lymphoma, including 69 patients with MZL. ${ }^{91}$ These patients had a median age of 67 years, they had received a median of two prior lines of therapy and $21 \%$ were refractory to their previous line of therapy. The ORR was $49 \%$ (complete responses, $16 \%$ ) and consistent across the MZL subtypes. After a median follow-up of 27 months, the median duration of response was not reached, with the estimated 2-year PFS rate being 50.5\%. Among all patients, the most frequent TEAE of any grade were diarrhea $(59 \%)$, nausea $(39 \%)$ and fatigue $(30 \%)$, with the grade $\geq 3$ ones being neutropenia $(11 \%)$ and diarrhea $(10 \%)$. TEAE of interest included opportunistic infections (grade $\geq 33.4 \%$ ), elevation of liver enzymes (all grades $20.2 \%$; grade $\geq 36.7 \%$ ) pneumonitis (all grades $1.4 \%$; grade $\geq 3$ $1.0 \%$ ) and non-infectious colitis (all grades 1.9\%; grade $\geq 30.5 \%$ ). Overall the agent was active and resulted in durable remissions with an acceptable safety profile and has received accelerated FDA approval for patients with relapsed MZL. Other PI3K inhibitors such as parsaclisib and zandelisib (NCT037685050) have also been explored in phase II studies. ${ }^{92}$

Although the focus of chimeric antigen receptor T-cell therapy (CAR-T) studies has mainly been on patients with aggressive histological subtypes such as relapsed/refractory diffuse large B-cell lymphoma, a few studies have looked at patients with indolent lymphomas. ZUMA-5 is an ongoing phase II study of axicabtagene ciloleucel in patients with relapsed/refractory indolent B-cell lymphoma. ${ }^{93}$ Jacobson et al. treated 146 patients, including 22 patients with MZL who had received two or more prior lines of therapy including a CD20 monoclonal antibody combined with an alkylating agent. The median age of the MZL patients was 66 years, the median number of prior lines of therapy was three and $52 \%$ had experienced a prior progression of disease within 24 months despite CD20 and alkylator-based therapy. The ORR for MZL patients was $85 \%$ (complete responses, $60 \%$ ) and after a median follow-up of 12.1 months, the median PFS was 11.8 months and the estimated 12 -month OS rate was $92.9 \%$. Cytokine release syndrome occurred in all 22 patients $(100 \%)$, with two $(9 \%)$ experiencing grade $\geq 3$ events and $15(68 \%)$ requiring tocilizumab. Typically for axicabtagene ciloleucel, the rate of neurological toxicity was substantial: $17(77 \%)$ patients experienced a neurological event and in nine $(41 \%)$ cases these were grade $\geq 3$ events. Steroids were required in $14(64 \%)$ of patients. Notably the rate of grade $\geq 3$ neurological toxicity appeared higher in MZL than in the follicular lymphoma cohort of the same study $(15 \%)$ and the median increases in analytes associated with axicabtagene ciloleucel toxicity were higher in patients with MZL than in those with follicular lymphoma. Although these results were disappointing, the number of patients with MZL was small and results are preliminary. In the 
ongoing TRANSCEND FL study (NCT04245839) patients with relapsed/refractory follicular lymphoma and MZL are being treated with lisocabtagene maraleucel. This and other studies will help to define the role of anti-CD19 CAR T cells in this disease.

Lenalidomide and rituximab is an active combination in patients with MZL. Leonard et al. included 63 patients with relapsed/refractory MZL (18\% of the study population) in the AUGMENT study, in which patients with indolent B-cell lymphoma were randomized to either rituximab or rituximab and lenalidomide. ${ }^{94}$ Overall, the study indicated an improvement in PFS (hazard ratio $=0.46$ ) from the addition of lenalidomide although this did not reach statistical significance in the small subset of patients with MZL. A phase II trial in treatmentnaïve patients resulted in an ORR of $93 \%$ (complete responses, $70 \%$ ). ${ }^{95}$ In a report of the long term follow-up of the MZL subset of this study, the median PFS was 59.8 months and the 5 -year OS was $96 \%{ }^{96}$

\section{Future directions}

The COUP-1 single-arm, phase II study (NCT03474744) is evaluating copanlisib and rituximab combination therapy in treatment-naive and relapsed MZL patients ineligible for local therapy. ${ }^{22}$ The German Lymphoma Alliance has also planned the POLE-1 trial (NCT03474744), a single-arm, phase II German and Italian collaborative study designed to evaluate the clinical performance of pembrolizumab in treatment-naïve and relapsed-confirmed MZL patients with nodal, extranodal, or splenic disease who are ineligible for local therapy. The German Lymphoma Alliance's OLYMP-1 trial (NCT03322865) is a single-arm phase II study that is designed to evaluate the clinical performance of obinutuzumab as a single agent in treatment-naïve MZL patients with nodal, extranodal, or splenic disease who are ineligible for local therapy. The IELSG38 study (NCT018085990), which investigated chlorambucil in combination with subcutaneous rituximab in patients with MALT lymphoma, has completed its enrollment phase, and follow-up and analysis is now ongoing. The IELSG48 randomized phase III study is planned to compare the clinical performance of rituximab single-agent therapy with that of rituximab combined with acalabrutinib in patients with splenic MZL in the first-line setting. The IELSG49 study (NCT04646395) is a run-in pilot study of tafasitamab (an anti-CD19 antibody) in combination with acalabrutinib in patients with relapsed or refractory MZL in whom previous systemic therapy has failed. The ongoing MALIBU-IELSG47 study
(NCT03697512) is evaluating ibrutinib plus rituximab combination therapy in untreated MZL, including extranodal MZL, splenic MZL, and nodal MZL. The primary endpoints of the MALIBU study are complete response at 12 months and progression-free survival at 5 years.

\section{Conclusions}

MZL are a group of indolent B-cell lymphomas with considerable heterogeneity in terms of clinical presentation, biology, etiology and therapeutic approaches. Most patients with limited stage MALT lymphoma have an excellent prognosis with either antibiotics (H. pylori-associated gastric MALT) or radiotherapy (gastric and nongastric sites). In the absence of symptoms, splenic MZL can be observed, while symptomatic patients can be managed with rituximab monotherapy or eventually splenectomy or chemo-immunotherapy if needed. Patients with nodal MZL can be managed in a similar fashion to those with follicular lymphoma. Histological transformation is rare but associated with inferior outcomes and should be managed with anthracycline-based chemo-immunotherapy. Newer targeted agents including BTK inhibitors, PI3K inhibitors, and immunomodulatory drugs are active in patients with relapsed/refractory disease. At present, the role of CAR T-cell therapy in MZL is under investigation in several trials. Future studies will define more active novel combinations.

\section{Disclosures}

CYC has received fees for consulting and advisory services and honoraria from Roche, Janssen, MSD, Gilead, Ascentage Pharma, AstraZenecca, Lilly, TG therapeutics, Beigene, Novartis, and BMS; research funding from BMS, Roche, Abbvie; and travel expenses from Roche. TMH has participated in data monitoring committees for Seagen and Tess Therapeutics, has sat on scientific advisory boards for Eli Lilly \& Co., Morphosys, Incyte, Biegene, and Loxo Oncology; he receives no personal compensation for these activities. His institution receives the compensation. $D R$ receives no personal compensation. His institution has received honoraria from AbbVie, AstraZeneca, and Janssen; and research grants from AbbVie, AstraZeneca, and Janssen. EZ's institution has received research support from AstraZeneca, Celgene, Incyte, Janssen, Merck, and Roche; honoraria for advisory boards services from Beigene, Celgene, Incyte Janssen, Merck, Roche, Celltion Healthcare, and Kyte (a Gilead Company); and travel grants from Abbvie and Roche.

\section{Contributions}

All authors revised and approved the manuscript.

\section{References}

1. Reid R, Friedberg JW. Management of marginal zone lymphoma. Oncology (Williston Park). 2013;27(9):840, 842, 844.

2. Sriskandarajah P, Dearden CE. Epidemiology and environmental aspects of marginal zone lymphomas. Best Pract Res Clin Haematol. 2017;30(1-2):84-91.

3. Cerhan JR, Habermann TM. Epidemiology of marginal zone lymphoma. Ann Lymphoma. 2021;5:1.
4. Swerdlow SH, Campo E, Harris NL, et al. WHO Classification of Tumours of Haematopoietic and Lymphoid Tissues. Revised Fourth Edition. IARC, 2017.

5.Zucca E, Bertoni F. The spectrum of MALT lymphoma at different sites: biological and therapeutic relevance. Blood. 2016;127(17):2082-2092

6. Teras LR, DeSantis CE, Cerhan JR, Morton LM, Jemal A, Flowers CR. 2016 US lymphoid malignancy statistics by World Health Organization subtypes. CA
Cancer I Clin. 2016;66(6):443-459.

7. Bracci PM, Benavente Y, Turner JJ, et al. Medical history, lifestyle, family history, and occupational risk factors for marginal zone lymphoma: the InterLymph NonHodgkin Lymphoma Subtypes Project. J Natl Cancer Inst Monogr. 2014;2014 (48):52-65.

8. Zucca E, Arcaini L, Buske C, et al. Marginal zone lymphomas: ESMO clinical practice guidelines for diagnosis, treatment and follow-up. Ann Oncol. 
2020;31(1):17-29

9. Isaacson P, Wright DH. Malignant lymphoma of mucosa-associated lymphoid tissue. A distinctive type of B-cell lymphoma. Cancer. 1983;52(8):1410-1416.

10. Maeshima AM, Taniguchi H, Toyoda K, et al. Clinicopathological features of histological transformation from extranodal marginal zone B-cell lymphoma of mucosa-associated lymphoid tissue to diffuse large B-cell lymphoma: an analysis of 467 patients. Br J Haematol. 2016;174(6):923-931.

11. Alderuccio JP, Zhao W, Desai A, et al. Risk factors for transformation to highergrade lymphoma and its impact on survival in a large cohort of patients with marginal zone lymphoma from a single institution. J Clin Oncol. 2018;36(34): 3370-3380.

12. Du MQ. MALT lymphoma: a paradigm of NF-kappaB dysregulation. Semin Cancer Biol. 2016;39:49-60

13. Raderer M, Wöhrer S, Streubel B, et al. Assessment of disease dissemination in gastric compared with extragastric mucosa-associated lymphoid tissue lymphoma using extensive staging: a singlecenter experience. J Clin Oncol. 2006;24(19):3136-3141.

14. Alderuccio JP, Isrow D, Reis IM, et al. Diagnostic bone marrow biopsy in patients with stage I EMZL treated with radiation therapy: needed or not? Blood. 2020;135(15):1299-1302.

15. Chae H, Cho H, Sa H-S, et al. The limited role of comprehensive staging work-up in ocular adnexal extranodal marginal zone lymphoma of mucosa-associated lymphoid tissue type (MALToma) with excellent prognosis. Br J Haematol. 2021;193 (4):848-851.

16. Thieblemont C, Cascione L, Conconi A, et al. A MALT lymphoma prognostic index. Blood. 2017;130(12):1409-1417.

17. National Comprehensive Cancer Network. National Comprehensive Cancer Network (NCCN) guidelines - Bcell lymphomas 2017 November 15, 2017; version 6

18.Zucca E, Copie-Bergman C, Ricardi U, Thieblemont C, Raderer M, Ladetto M. Gastric marginal zone lymphoma of MALT type: ESMO clinical practice guidelines for diagnosis, treatment and follow-up. Ann Oncol. 2013;24(Suppl 6):vi144-148.

19. Liu H, Ruskon-Fourmestraux A, Lavergne-Slove A, et al. Resistance of $t(11 ; 18)$ positive gastric mucosa-associated lymphoid tissue lymphoma to Helicobacter pylori eradication therapy. Lancet. 2001;357(9249):39-40.

20. Ryu KD, Kim GH, Park SO, et al. Treatment outcome for gastric mucosaassociated lymphoid tissue lymphoma according to Helicobacter pylori infection status: a single-center experience. Gut Liver. 2014;8(4):408-414.

21. Ferreri AJ, Cecchetti C, Kiesewetter B, et al. Clarithromycin as a "repurposing drug" against lymphomas: safety and efficacy profiles in 55 patients with extranodal marginal zone lymphoma (EMZL). Hematol Oncol. 2017;35(S2):86-87.

22. Saifi O, Lester SC, Rule W, et al. Comparable efficacy of reduced dose radiation therapy for the treatment of early stage gastric extranodal marginal zone lymphoma of mucosa-associated lymphoid tissue. Adv Radiat Oncol. 2021;6(4):100714
23. Goda JS, Gospodarowicz M, Pintilie M et al. Long-term outcome in localized extranodal mucosa-associated lymphoid tissue lymphomas treated with radiotherapy. Cancer. 2010;116(16):3815-3824

24. Martinelli G, Laszlo D, Ferreri AJ, et al. Clinical activity of rituximab in gastric marginal zone non-Hodgkin's lymphoma resistant to or not eligible for antiHelicobacter pylori therapy. J Clin Oncol. 2005;23(9):1979-1983.

25.Zucca E, Conconi A, Laszlo D, et al. Addition of rituximab to chlorambucil produces superior event-free survival in the treatment of patients with extranodal marginal-zone B-cell lymphoma: 5-year analysis of the IELSG-19 randomized study. J Clin Oncol. 2013;31(5):565-572.

26. Desai A, Joag MG, Lekakis L, et al. Longterm course of patients with primary ocular adnexal MALT lymphoma: a large single-institution cohort study. Blood. 2017;129(3):324-332.

27. Kiesewetter B, Raderer M. Antibiotic therapy in nongastrointestinal MALT lymphoma: a review of the literature. Blood. 2013;122(8):1350-1357

28. Ferreri AJ, Ponzoni M, Guidoboni M, et al. Regression of ocular adnexal lymphoma after Chlamydia psittaci-eradicating antibiotic therapy. I Clin Oncol. 2005;23(22):5067-5073.

29. Teckie S, Oi S, Lovie S, et al. Long-term outcomes and patterns of relapse of early-stage extranodal marginal zone lymphoma treated with radiation therapy with curative intent. Int J Radiat Oncol Biol Phys. 2015;92(1):130-137

30. MacManus MP, Roos D, O'Brien P, et al Prospective phase II trial of radiation therapy in localised non-gastric marginal zone lymphoma with prospective evaluation of autoimmunity and Helicobacter pylori status: TROG 05.02/ALLG NHL15. Eur J Cancer. 2021;152:129-138.

31. de la Fuente MI, Haggiagi A, Moul A, et al. Marginal zone dural lymphoma: the Memorial Sloan Kettering Cancer Center and University of Miami experiences. Leuk Lymphoma. 2017;58(4):882-888

32. Sunderland AJ, Steiner RE, Al Zahrani M, et al. An international multicenter retrospective analysis of patients with extranodal marginal zone lymphoma and histologically confirmed central nervous system and dural involvement. Cancer Med. 2020;9(2):663-670

33. Jackson AE, Mian M, Kalpadakis C, et al. Extranodal marginal zone lymphoma of mucosa-associated lymphoid tissue of the salivary glands: a multicenter, international experience of 248 patients (IELSG 41). Oncologist. 2015;20(10): 1149-1153.

34. Zelenetz AD, Gordon LI, Abramson JS, et al. NCCN guidelines insights: B-cell lymphomas, version 3.2019. J Natl Compr Canc Netw. 2019;17(6):650-661.

35. Oh SY, Kim WS, Kim JS, et al. Phase II study of R-CVP followed by rituximab maintenance therapy for patients with advanced marginal zone lymphoma: Consortium for Improving Survival of Lymphoma (CISL) study. Cancer Commun (Lond). 2019;39(1):58

36. Salar A, Domingo-Domenech E, Panizo $\mathrm{C}$, et al. First-line response-adapted treatment with the combination of bendamustine and rituximab in patients with mucosa-associated lymphoid tissue lymphoma (MALT2008-01): a multicentre, single-arm, phase 2 trial. Lancet
Haematol. 2014:1(3):e104-111.

37. Alderuccio JP, Beaven AW, Shouse G, et al. Frontline bendamustine and rituximab in extranodal marginal zone lymphoma: an international analysis. Blood. 2020;136(Suppl 1):2-3.

38. Knauf W, Abenhardt W, Koenigsmann M, et al. Rare lymphomas in routine practice - treatment and outcome in marginal zone lymphoma in the prospective German Tumour Registry Lymphatic Neoplasms. Hematol Oncol. 2021;39(3): 313-325.

39. Thieblemont C, Molina T, Davi F Optimizing therapy for nodal marginal zone lymphoma. Blood. 2016;127(17): 2064-2071.

40. Pileri S, Ponzoni M. Pathology of nodal marginal zone lymphomas. Best Pract Res Clin Haematol. 2017;30(1):50-55.

41. Conconi A, Franceschetti S, Aprile von Hohenstaufen K, et al. Histologic transformation in marginal zone lymphomas. Ann Oncol. 2015;26(11):2329-2335

42. Arcaini L, Paulli M, Boveri E, et al. Splenic and nodal marginal zone lymphomas are indolent disorders at high hepatitis C virus seroprevalence with distinct presenting features but similar morphologic and phenotypic profiles. Cancer. 2004 100(1):107-115.

43. van den Brand $M$, van Krieken JH Recognizing nodal marginal zone lymphoma: recent advances and pitfalls. A systematic review. Haematologica. 2013; 98(7):1003-1013

44. Spina V, Khiabanian H, Messina M, et al. The genetics of nodal marginal zone lymphoma. Blood. 2016;128(10):1362-1373.

45. Starr AG, Caimi PF, Fu P, et al. Dual institution experience of nodal marginal zone lymphoma reveals excellent long-term outcomes in the rituximab era. $\mathrm{Br}$ Haematol. 2016;175(2):275-280

46. Heilgeist A, McClanahan F, Ho AD, Witzens-Harig M. Prognostic value of the Follicular Lymphoma International Prognostic Index score in marginal zone lymphoma: an analysis of clinical presentation and outcome in 144 patients. Cancer. 2013;119(1):99-106.

47. Olszewski AJ, Castillo JJ. Survival of patients with marginal zone lymphoma: analysis of the Surveillance, Epidemiology, and End Results database. Cancer. 2013;119(3):629-638.

48. Arcaini L, Besson C, Frigeni M, et al Interferon-free antiviral treatment in $\mathrm{B}$ cell lymphoproliferative disorders associated with hepatitis $C$ virus infection. Blood. 2016;128(21):2527-2532

49. Kelaidi C, Rollot F, Park S, et al. Response to antiviral treatment in hepatitis $C$ virusassociated marginal zone lymphomas. Leukemia. 2004;18(10):1711-1716

50. Kang HJ, Kim WS, Kim SJ, et al. Phase II trial of rituximab plus CVP combination chemotherapy for advanced stage marginal zone lymphoma as a first-line therapy: Consortium for Improving Survival of Lymphoma (CISL) study. Ann Hematol. 2012;91(4):543-551.

51. Rummel MJ, Niederle N, Maschmeyer G, et al. Bendamustine plus rituximab versus CHOP plus rituximab as first-line treatment for patients with indolent and mantle-cell lymphomas: an open-label, multicentre, randomised, phase 3 non-inferiority trial. Lancet. 2013;381(9873):12031210

52. Brown JR, Friedberg JW, Feng Y, et al. A phase 2 study of concurrent fludarabine 
and rituximab for the treatment of marginal zone lymphomas. Br J Haematol. 2009;145(6):741-748.

53. Ferrario A, Pulsoni A, Olivero B, et al. Fludarabine, cyclophosphamide, and rituximab in patients with advanced, untreated, indolent B-cell nonfollicular lymphomas: phase 2 study of the Italian Lymphoma Foundation. Cancer. 2012; 118(16):3954-3961.

54. Laribi K, Tempescul A, Ghnaya H, et al. The bendamustine plus rituximab regimen is active against primary nodal marginal zone B-cell lymphoma. Hematol Oncol. 2017;35(4):536-541.

55. Arcaini L, Rossi D, Paulli M. Splenic marginal zone lymphoma: from genetics to management. Blood. 2016;127(17):20722081.

56. Kalpadakis C, Pangalis GA, Angelopoulou MK, Vassilakopoulos TP. Treatment of splenic marginal zone lymphoma. Best Pract Res Clin Haematol. 2017;30(1-2):139-148.

57. Rossi D, Trifonov V, Fangazio M, et al. The coding genome of splenic marginal zone lymphoma: activation of NOTCH2 and other pathways regulating marginal zone development. J Exp Med. 2012;209 (9):1537-1551.

58. Swerdlow SH, Kuzu I, Dogan A, et al. The many faces of small $\mathrm{B}$ cell lymphomas with plasmacytic differentiation and the contribution of MYD88 testing. Virchows Arch. 2016;468(3):259-275.

59. Santos TSd, Tavares RS, Farias DLCd. Splenic marginal zone lymphoma: a literature review of diagnostic and therapeutic challenges. Rev Bras Hematol Hemoter. 2017;39(2):146-154

60. Piris MA, Onaindia A, Mollejo M. Splenic marginal zone lymphoma. Best Pract Res Clin Haematol. 2017:30(1-2):56-64

61. Flinn I, van der Jagt R, Chang JE, et al. First-line treatment of iNHL or MCL patients with BR or R-CHOP/R-CVP: results of the BRIGHT 5-year follow-up study. J Clin Oncol. 2017;35(15 suppl): 7500

62. Rummel MJ, Koenigsmann M, Chow KU, et al. Two years rituximab maintenance vs, observation after first line treatment with bendamustine plus rituximab (B-R) in patients with marginal zone lymphoma (MZL): results of a prospective, randomized, multicenter phase 2 study (the StiL NHL7-2008 MAINTAIN trial). J Clin Oncol. 2018;36(15 suppl):7515.

63. Kalpadakis C, Pangalis GA, Sachanas S, et al. Rituximab monotherapy in splenic marginal zone lymphoma: prolonged responses and potential benefit from maintenance. Blood. 2018;132(6):666670

64. Williams ME, Hong F, Gascoyne RD, et al. Rituximab extended schedule or retreatment trial for low tumour burden non-follicular indolent B-cell nonHodgkin lymphomas: Eastern Cooperative Oncology Group protocol E4402. Br J Haematol. 2016;173(6):867875.

65. Alderuccio JP, Zhao W, Desai A, et al. Short survival and frequent transformation in extranodal marginal zone lymphoma with multiple mucosal sites presentation. Am J Hematol. 2019;94(5):585596.

66. Hsu A, Kurt H, Zayac AS, Olszewski AJ. CD5 expression in marginal zone lymphoma predicts differential response to rituximab or bendamustine/rituximab.
Leuk Lymphoma. 2021 Sep 1. [Epub ahead of print]

67. Bastidas-Mora G, Bea S, Navarro A, et al. Clinico-biological features and outcome of patients with splenic marginal zone lymphoma with histological transformation. Br J Haematol. 2021 Sep 14. [Epub ahead of print]

68. Cheson BD, Fisher RI, Barrington SF, et al. Recommendations for initial evaluation staging, and response assessment of Hodgkin and non-Hodgkin lymphoma: the Lugano classification. J Clin Oncol. 2014;32(27):3059-3068.

69. Matutes E, Oscier D, Montalban C, et al. Splenic marginal zone lymphoma proposals for a revision of diagnostic, staging and therapeutic criteria. Leukemia. 2008;22(3):487-495

70. Copie-Bergman C, Gaulard P, LavergneSlove A, et al. Proposal for a new histological grading system for post-treatment evaluation of gastric MALT lymphoma Gut. 2003;52(11):1656.

71. Thieblemont C, Cascione L, Conconi A, et al. A MALT lymphoma prognostic index generated from the dataset of the ELSG-19 prospective clinical trial. Blood. 2017;130(12):1409-1417

72. Montalban C, Abraira V, Arcaini L, et al. Simplification of risk stratification for splenic marginal zone lymphoma: a point-based score for practical use. Leuk ymphoma. 2014;55(4):929-931.

73. Arcaini L, Lazzarino M, Colombo N, et al. Splenic marginal zone lymphoma: a prognostic model for clinical use. Blood. 2006;107(12):4643-4649.

74. Conconi A, Thieblemont C, Cascione L, et al. Early progression of disease predicts shorter survival in MALT lymphoma patients receiving systemic treatment. Haematologica. 2020;105(11):2592-2597.

75. Beal KP, Yeung HW, Yahalom J. FDG-PET scanning for detection and staging of extranodal marginal zone lymphomas of the MALT type: a report of 42 cases. Ann Oncol. 2005;16(3):473-480.

76. Albano D, Borghesi A, Bosio G, et al. Pulmonary mucosa-associated lymphoid tissue lymphoma: (18)F-FDG PET/CT and CT findings in 28 patients. $\mathrm{Br}$ Radiol. 2017;90(1079):20170311.

77. Schöder H, Noy A, Gönen M, et al. Intensity of 18fluorodeoxyglucose uptake in positron emission tomography distinguishes between indolent and aggressive non-Hodgkin's lymphoma. J Clin Oncol. 2005;23(21):4643-4651.

78. Noy A, Schoder H, Gonen M, et al. The majority of transformed lymphomas have high standardized uptake values (SUVs) on positron emission tomography (PET) scanning similar to diffuse large B-cell lymphoma (DLBCL). Ann Oncol. 2009;20 (3):508-512.

79. Noy A, de Vos S, Thieblemont C, et al Targeting Bruton tyrosine kinase with ibrutinib in relapsed/refractory marginal zone lymphoma. Blood 2017:129(16): 2224-2232.

80. Noy A, de Vos S, Coleman M, et al. Durable ibrutinib responses in relapsed/refractory marginal zone lymphoma: long-term follow-up and biomarker analysis. Blood Adv. 2020;4(22): 5773-5784

81. Davids MS, Roberts AW, Seymour JF, et al. Phase I first-in-human study of venetoclax in patients with relapsed or refractory non-Hodgkin lymphoma. J Clin Oncol. 2017:35(8):826-833
82. Handunnetti SM, Khot A, Anderson MA et al. Safety and efficacy of ibrutinib in combination with venetoclax in patients with marginal zone lymphoma: preliminary results from an open label, phase II study. Blood. 2019:134(Suppl_1):3999.

83. Opat S, Tedeschi A, Linton K, et al. The MAGNOLIA trial: zanubrutinib, a nextgeneration Bruton tyrosine kinase inhibitor, demonstrates safety and efficacy in relapsed/refractory marginal zone lymphoma. Clin Cancer Res. 2021 Sep 15. [Epub ahead of print]

84. Gopal AK, Kahl BS, de Vos S, et al. PI3Kס inhibition by idelalisib in patients with relapsed indolent lymphoma. N Engl J Med. 2014;370(11):1008-1018.

85. Martin P, Armas A, Gopal AK, et al. Idelalisib monotherapy and durable responses in patients with relapsed or refractory marginal zone lymphoma (MZL). Blood. 2015;126(23):1543

86. Cheah CY, Nastoupil LJ, Neelapu SS, Forbes SG, Oki Y, Fowler NH Lenalidomide, idelalisib, and rituximab are unacceptably toxic in patients with relapsed/refractory indolent lymphoma. Blood. 2015;125(21):3357-3359.

87. Gilead Sciences Inc. Idelalisib Urgent Safety Letter. 2016.

88. Lampson BL, Kasar SN, Matos TR, et al. Idelalisib given front-line for treatment of chronic lymphocytic leukemia causes frequent immune-mediated hepatotoxicity. Blood. 2016;128(2):195-203

89. Dreyling M, Santoro A, Mollica L, et al. Phosphatidylinositol 3-kinase inhibition by copanlisib in relapsed or refractory indolent lymphoma. J Clin Oncol. 2017;35(35):3898-3905.

90. Panayiotidis P, Follows GA, Mollica L, et al. Efficacy and safety of copanlisib in patients with relapsed or refractory marginal zone lymphoma. Blood Adv. 2021;5(3):823-828

91. Fowler NH, Samaniego F, Jurczak W, et al. Umbralisib, a dual PI3Kס/CK1ع inhibitor in patients with relapsed or refractory indolent lymphoma. I Clin Oncol. 2021;39(15):1609-1618.

92. Phillips TJ, Corradini P, Gurion R, et al Phase 2 study evaluating the efficacy and safety of parsaclisib in patients with relapsed or refractory marginal zone lymphoma (CITADEL-204). Blood. 2020;136 (Suppl 1):27-28.

93. Jacobson C, Chavez JC, Sehgal AR, et al. Primary analysis of Zuma-5: a phase study of axicabtagene ciloleucel (axi-cel) in patients with relapsed/refractory $(\mathrm{R} / \mathrm{R})$ indolent non-Hodgkin lymphom (iNHL). Blood. 2020;136(Suppl 1):40-41.

94. Leonard JP, Jung S-H, Johnson J, et al. Randomized trial of lenalidomide alone versus lenalidomide plus rituximab in patients with recurrent follicular lymphoma: CALGB 50401 (Alliance). J Clin Oncol. 2015;33(31):3635-3640

95. Fowler NH, Davis RE, Rawal S, et al. Safety and activity of lenalidomide and rituximab in untreated indolent lymphoma: an open-label, phase 2 trial. Lancet Oncol. 2014;15(12):1311-1318.

96. Becnel MR, Nastoupil LJ, Samaniego F, et al. Lenalidomide plus rituximab $(\mathrm{R}(2))$ in previously untreated marginal zone lymphoma: subgroup analysis and long-term follow-up of an open-label phase 2 trial. Br J Haematol. 2019;185(5):874-882 